\title{
Salivary and serum hyaluronic acid concentrations in patients with Sjögren's syndrome
}

\author{
Moshe Tishler, Ilana Yaron, Idit Shirazi, Michael Yaron
}

\begin{abstract}
Objective-To evaluate salivary hyaluronic acid (HA) concentration in patients with primary Sjögren's syndrome (SS).

Methods-Salivary and serum HA concentrations were evaluated using a radiometric assay. Thirty nine patients with SS served as the study group and their results were compared with 19 patients having clinical symptoms and signs of dry mouth and with 10 normal controls.

Results-Salivary HA concentrations were significantly increased $(p<0.05)$ in the 39 patients with SS compared with the 19 patients with dry mouth and the 10 normal controls $(240.7$ (38.5) $v 99.8$ (14.6) and 91.3 (7.9) $\mathrm{ng} / \mathrm{ml}$, respectively) (mean (SEM)). No significant differences were noted in the serum HA concentrations between the three groups (42 (3.9) $v 36.3$ (4.1) and $32(4.3) \mathrm{ng} / \mathrm{ml}$, respectively) (mean (SEM)). No correlation could be found between salivary HA concentrations and the focus score of lip biopsies, nor between salivary HA concentrations and erythrocyte sedimentation rate or other serological tests.

Conclusion-Increased salivary HA concentrations can serve as a marker of local inflammation and may be of value in the diagnosis of SS.

(Ann Rheum Dis 1998;57:506-508)
\end{abstract}

Sjögren's syndrome (SS) is an autoimmune disorder affecting mainly the exocrine glands, thus causing dryness of the eyes and mouth. ${ }^{1}$ Salivary gland involvement in SS has been evaluated traditionally by salivary flow rate, scintigraphy, and lip biopsy. ${ }^{2}$ The typical biopsy findings demonstrate a focal periductal infiltrate composed of mononuclear cells, predominantly $\mathrm{CD}_{4}+\mathrm{T}$ lymphocytes. ${ }^{3}$ Furthermore, recent studies have shown that epithelial salivary gland cells produce large amounts of mRNA for various proinflammatory cytokines including interleukin

Table 1 Clinical and serological data of the study groups

\begin{tabular}{|c|c|c|c|}
\hline & SS group $(n=36)$ & Dry mouth group $(n=19)$ & Normal controls $(n=10)$ \\
\hline Age (y) (SD) & $58.3(11.2)$ & $61.3(9.6)$ & $62.1(12.3)$ \\
\hline Disease duration (y) (SD) & $7.2(2.2)$ & $6.1(3.1)$ & - \\
\hline $\operatorname{Sex}(M / F)$ & $2 / 34$ & $2 / 17$ & $2 / 8$ \\
\hline $\mathrm{RF}>1: 160(\%)$ & 70 & 10 & 0 \\
\hline ANF $>1: 80(\%)$ & 66 & 12 & 0 \\
\hline Anti-Ro antibodies (\%) & 55 & 0 & 0 \\
\hline Anti-La antibodies (\%) & 11 & 0 & 0 \\
\hline Extraglandular complications (\%) & 8 & - & - \\
\hline Salivary flow rate $(\mathrm{ml} / \mathrm{min})(\mathrm{SD})$ (non-stimulated) & $0.07(0.02)$ & $0.1(0.02)$ & $\mathrm{ND}$ \\
\hline
\end{tabular}

$\mathrm{ND}=$ Not done.
(IL) 1, IL6, and IL10. ${ }^{4}$ The concept that salivary analysis could be used as a diagnostic tool is attractive because it might spare biopsy procedure in some patients. Recently, we and others have shown that increased concentrations of salivary eicosanoids as well as IL6 may serve as a marker of local inflammation in $\mathrm{SS}^{.-7}$ Hyaluronic acid (HA), which is an unbranched polysaccharide, has been found to be an indicator of connective tissue turnover. Increased serum concentrations of HA has been found in lung and liver diseases as well as in rheumatoid arthritis (RA). ${ }^{8-10}$ The purpose of our study was to investigate the possibility that increased HA concentrations might be found in the saliva of patients with SS as a consequence of a local inflammatory process.

\section{Methods}

STUDY GROUPS

Thirty nine consecutive patients with primary SS followed up at the SS Clinic, Department of Rheumatology, Tel Aviv Medical Centre, were enrolled in the study. All patients were diagnosed as having SS according to the newly proposed criteria of the EC Study Group. ${ }^{11}$ All patients had a positive lip biopsy specimen with a focus score $>1$, and biopsy specimens were read blindly by a pathologist without knowing details on patients' clinical data. None of the participating subjects had taken NSAIDs or immunosuppressive treatment for a month before salivary collection, nor had any apparent oral infection. Results from these patients were compared with data of 19 patients referred to the clinic with clinical symptoms and objective signs of dry mouth who did not meet the EC criteria for SS and had a negative lip biopsy specimen (“dry mouth" group). In 10 patients of this group the cause was found to be drug induced, one patient had sarcoidosis, and in eight patients no apparent disorder was detected. A group of 10 normal healthy people served as a control group. Table 1 shows the clinical and demographic data of the study groups. No differences were noted between the study groups as regards to age and salivary flow rates.
Rheumatology, Tel

Aviv-Souraski Medical

Hospital and Tel Aviv

University Sackler

School of Medicine, Tel

Aviv, Israe

Correspondence: Dr M

Tishler, Department of

Rheumatology, Tel

Aviv-Souraski Medica

Centre, Tel Aviv, Israel

64239.

Accepted for publication 1 June 1998 


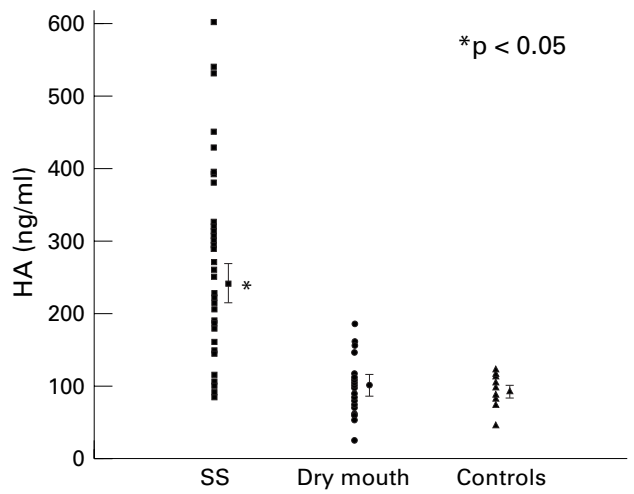

Figure 1 Salivary and serum hyaluronic acid concentrations in the study groups (mean (SEM)).

HYALURONIC ACID ASSAY

Saliva and blood samples were collected from patients at the same visit between 8 am and 10 am. After centrifugation they were immediately frozen and stored at $-20^{\circ} \mathrm{C}$ until processed. Whole unstimulated saliva was collected by spitting for 10 minutes into a test tube and its volume was recorded as previously described. ${ }^{6}$ The assay was carried out blindly with respect to diagnosis.

HA concentrations of blood and saliva were determined using a radiometric assay (Kabi Pharmacia, Uppsala, Sweden). The test is based on the use of specific hyaluronic acid binding proteins (HABP) isolated from bovine cartilage. The intra and interassay coefficients of variation are $5.2 \%$ and $6.4 \%$, respectively and the lower limit of detection is $10 \mu \mathrm{g} / 1$.

STATISTICAL ANALYSIS

Data for the different groups were initially evaluated using analysis of variance. The significance of differences was analysed by Wilcoxon signed rank tests. Significance was determined by $\mathrm{p}$ value of less than 0.05

\section{Results}

Figure 1 gives the results of HA concentrations in saliva and serum.

The mean (SEM) concentrations of salivary HA were significantly higher in SS patients (240.7 (38.5) $\mathrm{ng} / \mathrm{ml}$ ) than in patients with dry mouth (99.8 (14.6) $\mathrm{ng} / \mathrm{ml}$ ) and in normal healthy controls $(91.3(7.9) \mathrm{ng} / \mathrm{ml})(\mathrm{p}<0.05)$. The differences in salivary HA between the study groups remained also when HA concentrations in patients and controls were corrected with the amount of saliva obtained for testing. No change of results has been found when salivary HA was calculated according to the person's flow rate. No significant differences were recorded in the concentrations of HA in the serum between the three study groups (42 (3.9) $\mathrm{ng} / \mathrm{ml} v 36.3(4.1) \mathrm{ng} / \mathrm{ml}$ and 32 (4.3) $\mathrm{ng} / \mathrm{ml}$, respectively) (mean (SEM)).

No correlation was found between salivary HA concentrations and erythrocyte sedimentation rate, anti-Ro antibodies or antinuclear factor. Furthermore, salivary HA concentrations were not different between SS patients with focus score of 1 and 2 .

\section{Discussion}

The salivary glands are one of several major target organs of inflammation in primary SS, resulting in dry mouth (xerostomia) associated with reduction of secretory function. ${ }^{1}$ As xerostomia is non-specific and can result from a variety of causes in up to $20 \%$ of the general population, it is important to find an objective laboratory test to evaluate the diagnosis of SS in these patients. The presence of focal lymphocytic infiltration in the salivary glands of patients with SS led us to look for inflammatory markers in the saliva of these patients. In earlier studies, we and others have shown that increased salivary concentrations of eicosanoids $\left(\mathrm{PGE}_{2}, \mathrm{TXB}_{2}\right)$ and of IL6 might be a good marker to differentiate SS patients from those suffering from dry mouth without an accompanying disease..$^{5-7}$ HA was chosen for this study because it has been shown to be a marker for inflammation in various disorders. HA is an unbranched high molecular weight polysaccharide synthesised by connective tissue cells and is widely distributed in the body. Raised concentrations of HA have been shown in bronchoalveolar lavage of patients with sarcoidosis and idiopathic pulmonary fibrosis. ${ }^{8}$ Similarly, increased serum HA concentrations have been reported in various liver diseases where they serve as a marker for progressive liver damage, especially in primary biliary cirrhosis. ${ }^{9}$ Although increased serum HA is not specific for the diagnosis of RA as it could be detected in other forms of arthritides, it has been shown to be a useful marker of disease activity. ${ }^{10}$

A number of immune regulatory functions are associated with HA, notably its effects on T cells and in turn its production rate is stimulated by proinflammatory cytokines, such as IL1, IL6, and tumour necrosis factor. ${ }^{12} \mathrm{We}$ speculated that increased HA concentrations could be found in the saliva of SS patients as a consequence of local production. Therefore the finding of a significant increase in salivary HA in patients with primary SS as compared with a dry mouth group and normal controls is not surprising. To the best of our knowledge, these findings are unique and have not been described before. Indeed, our finding of increased HA concentrations in the saliva of patients with SS is in accordance with recent studies that showed large amounts of mRNA for IL1, IL6, and IL10 in the epithelial salivary glands of these patients. ${ }^{4}{ }^{13}$

Increased salivary HA concentrations in patients with SS could be explained by two mechanisms: (a) local production, (b) a loss of structural barriers in the gland parenchyma, allowing HA to enter saliva from the serum. However, the latter seems unlikely as studies of saliva composition in SS have shown that the epithelial barriers remain intact. ${ }^{14}$ Furthermore, in our study serum HA in all three groups studied were not statistically different, thus supporting the idea that increased salivary HA concentrations are a consequence of local production. We think that the "leak" of HA to the saliva rather than into the serum as well is probably because the total amount of HA produced by 
the salivary gland is small. This is in contrast with other diseases, such as RA, in which there are multiple joint effusions causing large quantities of HA to be released from the synovium into the serum. ${ }^{15}$ The fact that increased HA salivary concentrations were found in SS patients and not in patients with dry mouth despite similar flow rates, rules out the possibility that small salivary volume contributed to the increased concentrations. As evaluation of salivary gland involvement in SS is complicated and usually requires biopsy, we suggest that salivary HA may be added to the list of markers that can be easily used in supporting the diagnosis of SS in patients presenting with dry mouth symptomatology. Of course, it should be borne in mind that it cannot be used as a marker of salivary disease severity or activity as has been shown in salivary IL6. ${ }^{6}$

Although HA is thought to be a good marker for collagen turnover and also of inflammation, we have no explanation for the fact that its concentrations do not correlate with either disease activity or severity. There is no doubt that a bigger control group with a wide age range is needed to calculate the sensitivity, and comparison with other autoimmune diseases could for SS clarify the specificity of this novel marker.

1 Talal N, Moutsopoulos HM, Kassan SS, eds. Sjögren's syndrome: clinical and immunological aspects. Berlin: Springer-Verlag, 1987.
2 Pennec YL, Letoux G, Leroy JP, Youinou P. Reappraisal of tests for xerostomia. Clin Exp Rheumatol 1993;11:523-8. Skopouli FN, Fox PC, Galanopoulou U, Atkinson JC, Jaffe 3 Skopouli FN, Fox PC, Galanopoulou U, Atkinson JC, Jaffe
ES, Moutsopoulos HM. T-cell sub-populations in the labial salivary gland histopathologic lesion of Sjögren's syndrome. J Rheumatol 1991;18:210-14.

4 Fox RI, Kang HI, Ando D, Abrams J, Pisa E. Cytokine mRNA expression in salivary gland biopsies of Sjögren's syndrome. J Immunol 1994;152:5532-9.

5 Tishler M, Yaron I, Raz A, Meyer FA, Yaron M. Salivary eicosanoid concentration in patients with Sjögren's syndrome. Ann Rheum Dis 1996;55:202-4.

6 Tishler M, Yaron I, Shirazi I, Yaron M. Increased salivary IL-6 levels in patients with primary Sjögren's syndrome. Arthritis Rheum 1996;39 (suppl):S68.

7 Grisius MM, Bermudez OK, Fox PC. Salivary and serum interleukin 6 in primary Sjögren's syndrome. J Rheumatol 1997;24:1089-91.

8 Cooper EH, Rathbone BJ. Clinical significance of the immunometric measurements of hyaluronic acid. Ann Clin immunometric measurements

9 Nyberg A, Engstrom-Laurent A, Löö FL. Serum hyaluronate in primary biliary cirrhosis - A biochemical marker for progressive liver damage. Hepatology 1988;8:142-6.

10 Emlin W, Niebour J, Flanders G, Rutledge J. Measurement of serum hyaluronic acid in patients with rheumatoid arthritis: correlation with disease activity. J Rheumatol 1996;23:974-8.

11 Vitali C, Bombardieri S, Moutsopoulos HM, Balestrieri G, Bencivelli W, Bernstein RM, et al. Preliminary criteria for the classification of Sjögren's syndrome: Results of a prospective concerted action supported by the European Community. Arthritis Rheum 1993;36:340-7.

12 Butler DM, Vitti GF, Leizer T, Hamilton JA. Stimulation of the hyaluronic acid levels of human synovial fibroblasts by recombinant human tumor necrosis factor $\alpha$, tumor necrosis factor $\beta$, interleukin- $1 \alpha$ and interleukin-1 $\beta$. Arthritis Ris factor $\beta$, interleukin-

13 Boumba D, Skopouli FN, Moutsopoulos HM. Cytokine mRNA expression in the labial salivary gland tissues from patients with primary Sjögren's syndrome. Br J Rheumatol 1995;34:326-33.

14 Atkinson JC, Travis WO, Pillemer SR, Bermudez D, Wolff A, Fox PC. Major salivary gland function in primary Sjögren's syndrome and its relationship to clinical features. J Rheumatol 1990;17:318-22.

15 Laurent TC, Laurent NB, Fraser JR. Serum hyaluronan as a disease marker. Ann Med 1996;28:241-53. 